\title{
A message from the new editor-in-chief
}

\section{Yasumasa Nishimura ${ }^{1}$}

Published online: 7 April 2020

(c) Japan Society of Clinical Oncology 2020

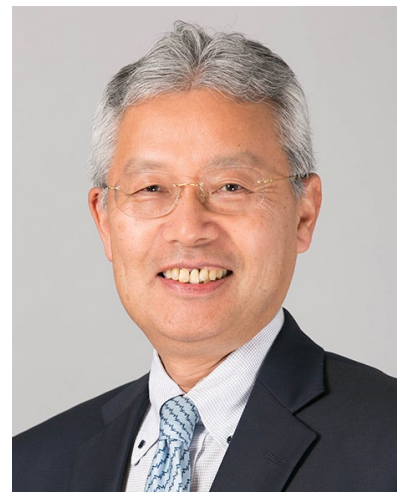

It is my great pleasure and honor to be appointed as the new editor-in-chief of the International Journal of Clinical Oncology (IJCO) in February 2020. The official journal of the Japan Society of Clinical Oncology (JSCO), IJCO published its first issue in May 1996. In the editorial of that issue, Professor Kazue Ozawa, who was the first editor-inchief, now editor emeritus, wrote that IJCO would provide an international forum for scientific communication between clinical oncologists both in Japan and overseas [1]. Fortunately, I was able to see the progress of this journal myself, as I have been involved in the editorial committee of IJCO since 1996.

I would like to summarize the development of IJCO briefly. The number of articles published in IJCO has grown significantly. Initially, IJCO had four issues per year. The frequency was increased to six issues annually in 1998, and then to 12 issues per year in 2019. MEDLINE is the US National Library of Medicine bibliographic database with a concentration of articles on biomedicine. IJCO has been indexed in MEDLINE since 2001. Researchers have

Yasumasa Nishimura

ynishi@med.kindai.ac.jp

1 Department of Radiation Oncology, Kindai University Faculty of Medicine, Osaka-Sayama, Japan been able to search articles in IJCO using MEDLINE, so it was the first stage for IJCO to become a truly international journal. Impact factor (IF) is used as one of the indicators of the quality of journals; it is a measure of the frequency with which the average article in a journal is cited in a particular year or period. With the great efforts of the successive editors-in-chief and editorial committees, our journal's IF increased gradually from 1.508 in $2009,1.410$ in 2011 , 2.170 in $2013,1.806$ in $2015,2.610$ in 2017 , and finally to 2.503 in 2018 .

Along with the increase in IF, the total number of submissions has risen: 517 in 2015, 585 in 2017, and 1017 in 2019. Looking at contributions by country, $33 \%$ of submissions came from Japan in 2019, 42\% from Asia excluding Japan, $8 \%$ from Europe, and 3\% from North America. In terms of new submissions by scientific area, medical oncology, surgical oncology, and urology are the three major areas accounting for approximately $20 \%$ each, followed by gynecology, basic science, radiation oncology, and pathology. Inversely, the acceptance rate decreased, with an acceptance rate in 2019 of $21.6 \%$. Thus, IJCO has become a real international journal of a multidisciplinary approach to cancer therapy through novel modalities in surgical treatment, radiation therapy, chemotherapy, and immunotherapy.

In this issue, special invited reviews on PD-1 blockade cancer immunotherapy have been published. We are pleased to present these special reviews on breakthrough research from Japan. This success story from the discovery of PD-1 in 1992 to clinical approval of PD-1 antibodies was written by Tasuku Honjyo et al. [2], who was a Nobel Prize laureate in 2018. Basic, preclinical, and clinical studies on PD-1 blockade cancer immunotherapy are reviewed in other articles. Clinical research is motivated by the desire to improve therapeutic outcomes by applying the knowledge that basic scientists have uncovered. One of the roles of IJCO is to publish this research.

The major task for IJCO now is to raise its quality even higher so that the journal becomes fully established in the world. Authors obviously want their research published in a journal with a higher IF, thus we must make our journal 
more attractive to them as well as to readers. Although many retrospective studies are submitted to our journal, most of them have no impact on the clinical practice of cancer treatment. In the era of evidence-based medicine, we need highquality clinical articles including prospective randomized studies. We truly appreciate every contribution to IJCO. It is our sincere hope that IJCO will continue to play its role globally as the most innovative and reliable source of information for clinical oncologists.

\section{Reference}

1. Ozawa K (1996) On launching the international journal of clinical oncology. Int J Clin Oncol 1:1
2. Chamoto K, Hatae R, Honjo T (2020) Current issues and perspectives in PD-1 blockade cancer immunotherapy. Int J Clin Oncol. https://doi.org/10.1007/s10147-019-01588-7

Publisher's Note Springer Nature remains neutral with regard to jurisdictional claims in published maps and institutional affiliations. 